\title{
The future of motorsport? An analysis of the attractiveness of motorsport for the Generation Z.
}

\section{4th November 2020}

\begin{abstract}
For generations, people have been fascinated by motorsport. However, the youngest generation pursues new values, interests and behaviors and consequently has different expectations of entertainment. In this regard, this research aims to determine the perceived attractiveness of motorsport for Generation Z. Three conceptually different racing series (Formula 1, Formula E, SimRacing) will be analysed in this research. In addition, the influence of generation-typical attitudes and interests (environmental awareness, experience orientation, technical affinity, sports interest) were examined for possible predictions on the perceived attractiveness of the three racing series. A standardized online survey was used as a main method of research. The results show that the general attractiveness of motorsport is low among the Generation Z. Even though the result is in principle negative, Formula 1 shows the highest attractiveness, followed by Formula $E$ and SimRacing in last place. The strongest prediction for the attractiveness of any racing series is provided by technical affinity. The results of this study suggest that in order to keep motorsport attractive in the long term, it is essential to pay more attention to Generation Z. Qualitative follow-up studies, which examine the needs and future expectations of the generation in relation to motorsport, could support the strategy and sustainable implementation of the future motorsport concept towards higher attractiveness.
\end{abstract}




\section{Formula 1}

- Existing since 1950

- Race duration: distance of at least $305 \mathrm{~km}$

- Drive: six-cylinder combustion engine

- Venues: official international race tracks

- Racing team/ manufactures develop their own racing cars

\section{Formula $\mathrm{E}$}

- Existing since 2014

- First fully electric motorsport series

- Race duration: 45min + 1lap (day event)

- Drive: electric drive

- Venues: international street courses in the major city centers

- "Unified cars"; only the drive train is developed by the respective racing team

- Involvement and activation of fans via social media

\section{SimRacing}

- Since 2018 recognized as official motorsport discipline (by the DMSB)

- Real race tracks are driven virtually (Hockenheimring, Silverstone..)

- Participation from home or at official tournaments also in arenas

- Broadcast: ProSiebenMaxx or online (e.g. Twitch)

\section{Introduction}

Motorsport is currently confronted with a number of challenges, such as the increasing ecological awareness of consumers, changing media consumption behaviors and decreasing sponsorship activities (Reuter, 2018). Traditional motorsport needs combustion engines - the one was difficult to imagine without the other. But also regarding this core attribute some newly developed alternatives are emerging. Electric racing series, virtual races or even roboraces with autonomous electric vehicles - many trends are currently tested (Audi AG, 2016). The target group for these racing series are primarily the younger generation. Especially with regard to the Generation Z, a change in values is evident.

Grown up in the spotlight of the internet, they are considered to be demanding, under constant media influence and in search of individuality (OC\&C Strategy Consultants, 2019). It is no secret that any kind of sport will only be successful in the long term if it fulfills the wishes and needs of this generation and is able and willing to transform in such a way that this new generation can be attracted and inspired for years to come (The Nielsen Company, 2019). Considering these developments, motorsport is currently trying to achieve exactly that: a long-term, successful existence through change by establishing new racing series. It is therefore essential to understand how these new racing series fit to the attitudes and interests of the next generation.

This research aims to provide initial insights into these issues by analyzing the current state of the attractiveness of motorsport and the new racing series from the perspective of the Generation Z. For this purpose, three conceptually different racing series will be utilized within the framework of this study - Formula 1, Formula E and the virtual SimRacing. 
The main focus of this study is to determine the perceived attractiveness of motorsport and the three different racing series for the Generation $Z$. Furthermore, the present study is also aimed at explaining this rating by analyzing the influence of generation-typical attitudes and interests on the perceived attractiveness of the different racing series. The knowledge gained from the research questions is intended to serve all stakeholders of motorsport as guidance for a future-oriented successful design of motorsport. Among others, this can be used as a basis for decision-making with regard to the overall strategy in planning phases by offering a development direction that reflects the interests of the Generation Z.

\section{Research Approach}

With regard to the research context and the research goal of measuring the current status of the attractiveness of various racing series for Generation $Z$, the authors decided on a quantitative research design. The target group of the standardized online questionnaire is the Generation Z, which for this research context represents persons born between 1995 to 2012. In order to make comparisons with other generations, the participation was accessible for everyone. However, in order to activate as many members of the Generation Z as possible, the recruitment was conducted via social media. The survey period was from March 27, 2020 to April 13, 2020. For the questionnaire only closed-ended questions were chosen to ensure greater objectivity. The questionnaire started with general questions on attitudes and interests, followed by questions on awareness, consumption, involvement and willingness to spend money on the three race series. The surveyed attitudes and interests were selected on the basis of various generational researches which revealed these characteristics as representative for the Generation $Z$. The participants were asked to express the degree of their agreement or disagreement with various statements relating to the object being measured, using a 6 level Likert scale.

\section{Key Research Questions}

- Is motorsport attractive for the Generation Z?

- Which race series is most attractive?

- Is there an effect of generation-specific attitudes and interests on the perceived attractiveness of a racing series? The factors considered in this research question is detailed in the chart below.

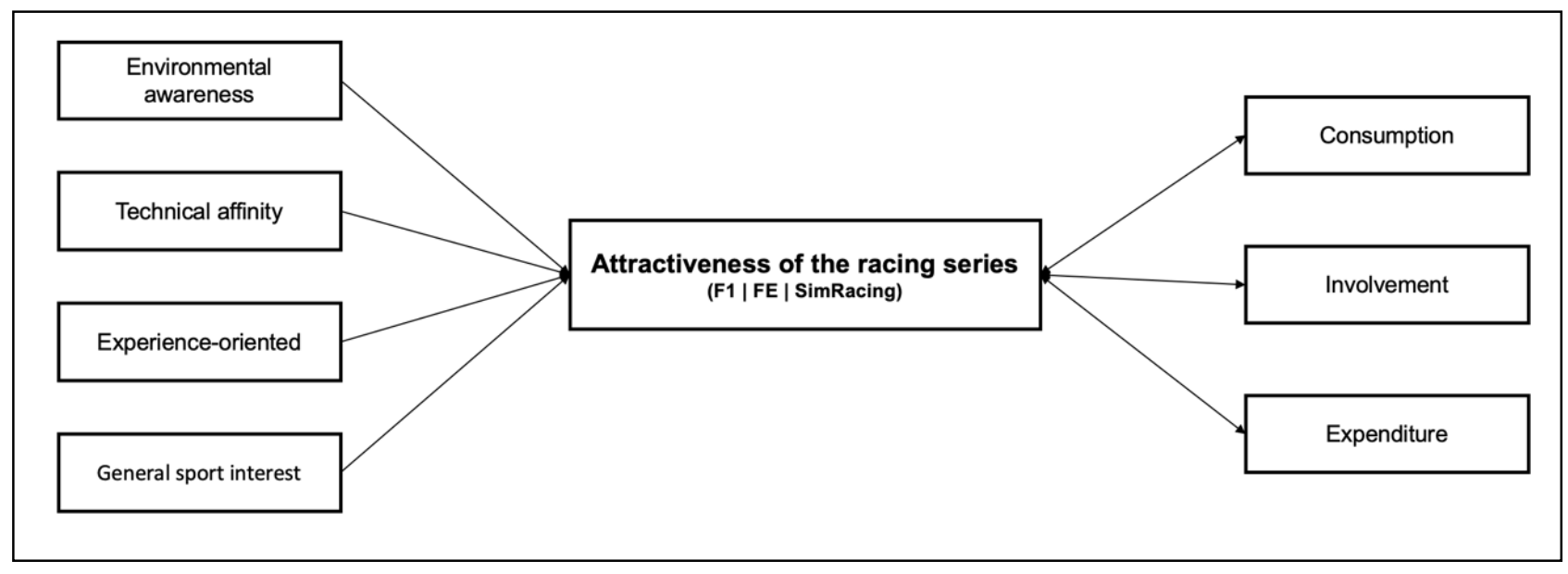




\section{Sample}

Sample Characteristics Gen Z

$(\mathrm{N}=243)$

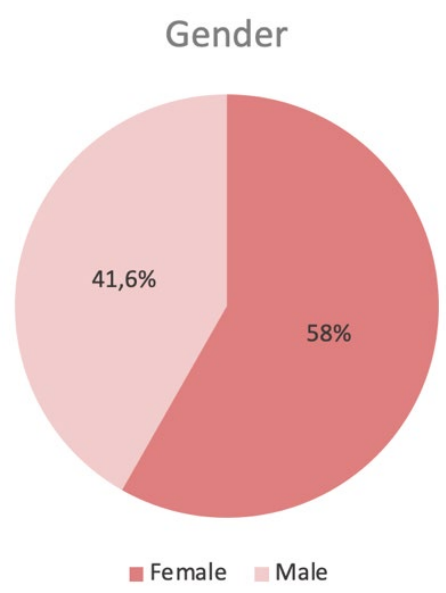

Current Employment Gen Z

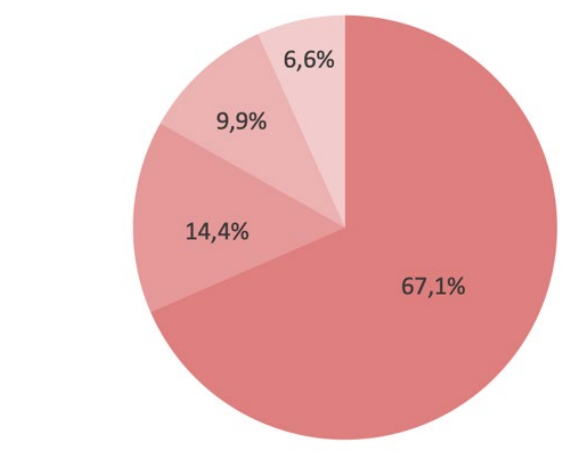

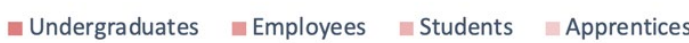

A total of 513 participants filled out the survey, of which 480 could be used after a first screening. The age range was from 12 years to 72 years. Of the 480 participants, 243 (50.6\%) belong to the Generation $Z$. The following results refer only to the sample that belongs to Generation $Z$ based on the previously defined definition ( $N=243$ ).

$58 \%$ of the sample are female, $41,6 \%$ male and 1 respondent stating a diverse gender $(0,04 \%)$. In terms of employment, undergraduates are in the majority with $67,1 \%$, followed by $14,4 \%$ in employment, $9,9 \%$ students, $6,6 \%$ apprentices, $0,8 \%$ self-employed and $1,2 \%$ with other jobs.

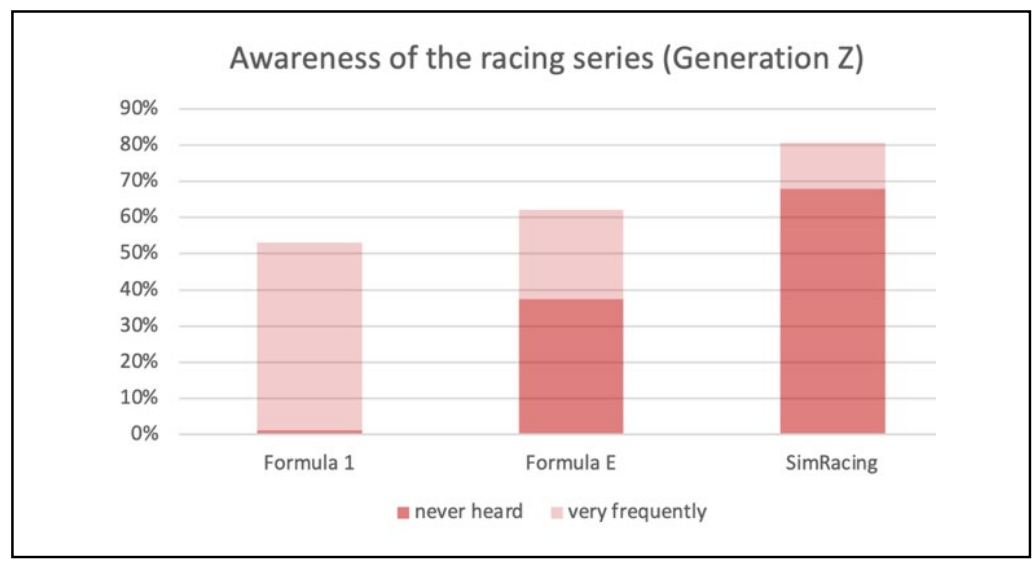

Formula 1 is the most famous racing series for Generation $Z_{\text {, }}$ whereas $67,9 \%$ have never heard of SimRacing. Only 37,4\% have never heard of Formula $\mathrm{E}$ before.

\section{Results: Research question $1 \& 2$}

By comparing the attractiveness of the general motorsport $(M=2,3 ; S D=1,13)$ with the test value of 3,5 , which is the average value of the 6-level Likert scale, the t-test shows that it is significantly lower than the test value. The summarizing conclusion is that the general motorsport has very low attractiveness among the Generation Z.

In a direct comparison, Formula $1(95 \%-\mathrm{CI}[2,56,2,93]), \mathrm{M}=2,74, \mathrm{SD}=1,52, \mathrm{p}<.001$ has the relatively highest attractiveness, followed by Formula $\mathrm{E}(95 \%-\mathrm{CI}[2,23,2,58]), \mathrm{M}=2,40, \mathrm{SD}=1,39, \mathrm{p}<.001$ and SimRacing (95\%$\mathrm{CI}[1,69,1,95]), \mathrm{M}=1,83, \mathrm{SD}=1,04, \mathrm{p}<.001$ in last place. 


\section{Multivariate data analysis}

In order to test whether the attractiveness of the racing series is affected by the interests and attitudes, a multiple linear regression analysis was performed for each racing series. As predictors the four generationtypical dimensions (environmental awareness, technical affinity, interest in sports and experience orientation) were deployed. The overall attractiveness of the different racing series was used as the dependent variable. This overall variable is based on the three variables mentioned in the beginning (consumption, involvement, expenditure), which were tested specifically for each race series. By using mean scale values, the related items were combined into a race series attractiveness variable.
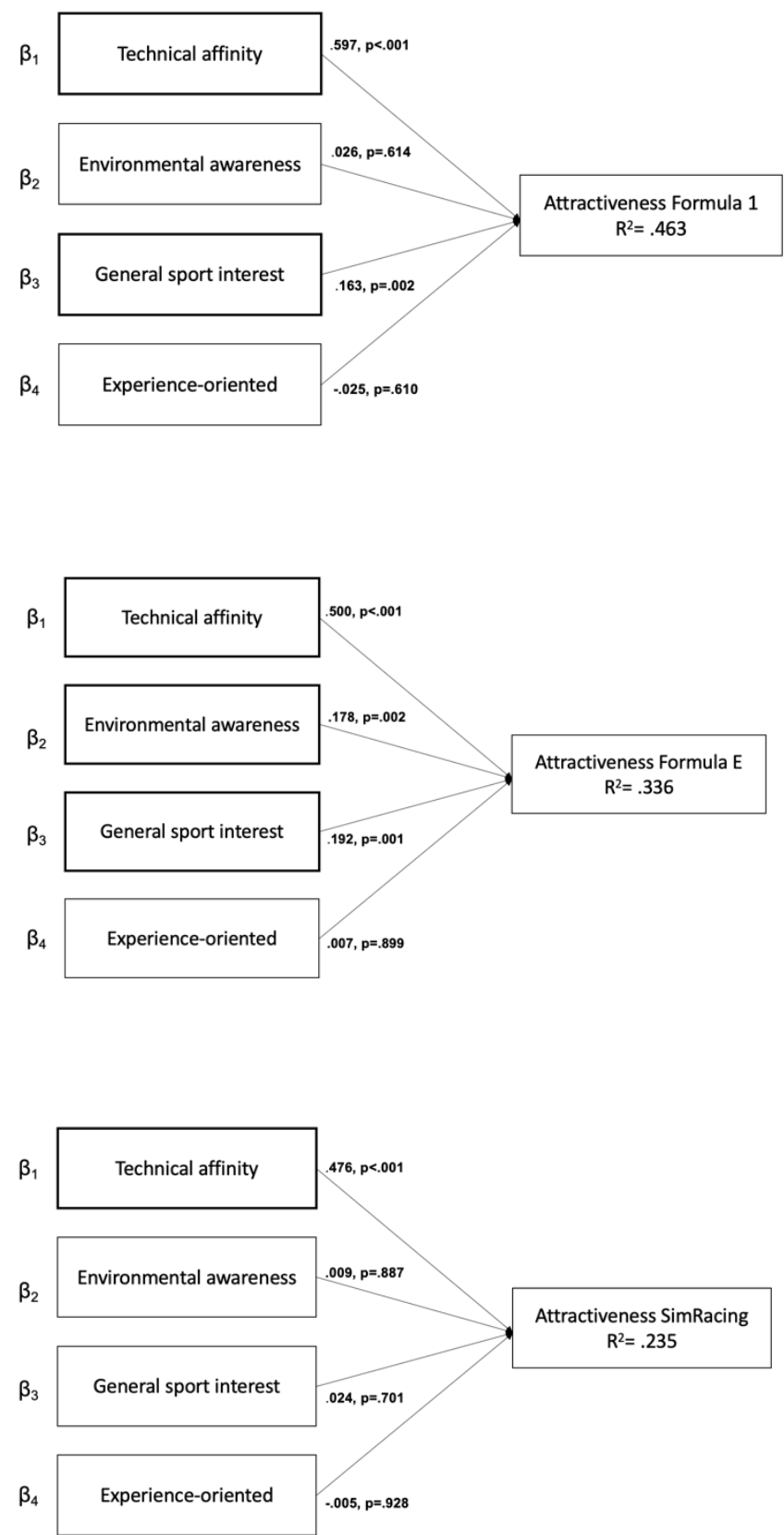

\section{Results: Formula 1}

The results of the multiple regression analysis show for Formula 1 that the technical affinity $\left(\beta_{1}=.597, p<.001\right)$ together with the sport interest $\left(\beta_{3}=.163, p=.002\right)$ of a person, are the strongest predictors for the attractiveness of this race series. Overall, the significant model accounts for $46.3 \%$ of the variation of the attractiveness of Formula 1, F $(4,238)=51,38, p<.001$.

\section{Results: Formula E}

For Formula $E$ the result shows that environmental awareness $\left(\beta_{2}=.178, p=.002\right)$ together with technical affinity $\left(\beta_{1}=.500, p<.001\right)$ and general sport interest $\left(\beta_{3}=.192, p=.001\right)$ provide a prediction of the attractiveness of this racing series. Overall, the model accounts for $33.6 \%$ of the variation of the attractiveness of the Formula $E, F(4,238)=30,17, p<.001$.

\section{Results: SimRacing}

For SimRacing, the significant model accounts for $23.5 \%$ of the variation of the attractiveness, $p<.001$. In this case, the technical affinity $\left(\beta_{1}=.476, p<.001\right)$ is the only significant predictor, $F(4,238)$ $=18,29, p<.001$. 


\section{Results: Explorative Data Analysis}

Additional analysis show that motorsport is significantly more attractive for men $(M=2,91, S D=1,13)$ than for women $(M=1,90, S D=0,93), t(188,91)=-7.40 ; p<.001$.

Related to the generations, there is no significant difference between Generation $Z(M=2,32, S D=1,13)$ and the older generations $(M=2,48, S D=1,00)$ regarding the attractiveness of motorsport, $t(473,40)=-1.56 ; p=.120$.

\section{Discussion}

Even though the alternative racing series are trying to adapt to the changes in behavior and attitudes of the Generation Z, the interest of this generation does not seem to have been awakened yet.

Due to the increasing environmental awareness and the higher consumption of online media by Generation $Z$, it was hypothesized that either the sustainable Formel $E$ or the virtual series Sim Racing would be most attractive to Generation Z. A potential explanation for the higher attractiveness of Formula 1 may be that it is also the best known racing series. Due to the familiarity and history of the racing series, it is possible that the participants refer to views formed in the past (Kuss, 2012). The phenomenon of the "mere-exposure-effect" can be considered as an additional explanation. According to this theory, individuals evaluate stimuli that are neutral for them more positively after repeated perception (Jonas \& Stroebe, 2007). With a rather neutral or indifferent opinion towards motorsport, the well-known Formula 1 performs better when explicitly asked.

The overall very negative result of SimRacing can be explained by the assumption that, due to the short existence of this racing series, Generation $Z$ has not yet formed an opinion about it.

It is worth mentioning the summarizing finding that technical affinity represents for all three racing series the strongest prediction of the attractiveness. It seems to be a decisive factor. However, people who are enthusiastic about innovations, cars and technology assume this general openness towards any kind of motorsport series. Furthermore, the general sport interest serves as predictor of the attractiveness of Formula 1 and Formula $\mathrm{E}$ but not for the Sim Racing. This result leads to the assumption that virtual racing is not yet understood as sport.

A final comparison of the attractiveness of motorsport between the generations shows no difference. Even if one might be supposedly surprised because motorsport in the past still functioned as a "mass sport", this result shows that motorsport is not only unattractive for Generation Z but also represents a low attractiveness for older generations.

\section{Limitation}

Due to the self-selected sample within the online survey, the participants have freely decided whether to participate in the survey, which limits the representativeness of the sample (Kuss, 2012). Furthermore, it should be mentioned that the requirement of homoscedasticity was not given in the multiple regressions. In the analysis of SimRacing, the requirement of the normal distribution of residuals was also not fulfilled.

Due to the deliberate choice of a 6 -step scale, the tendency towards the middle should be avoided, but the consequences of a resulting distortion due to a tendency decision should also be considered (Moosbrugger \& Kelava, 2008). 


\title{
Final Review \& Outlook
}

The results of the study contribute to the understanding of attitudes towards motorsport and thus to help this sport to bridge the gap towards the future generations. In particular, the results illustrate that there is a need for action and optimization regarding this sport. While the general attractiveness of motorsport is low among the Generation Z, it is particularly noteworthy that also the new alternatives do not arouse the interest of the younger generation. Further research is necessary to better understand the formation of attitudes and beliefs towards motorsport. As a next step, qualitative follow-up studies could be performed to better understand how motorsports should be designed so that it becomes attractive for Generation Z. In this regard, the needs and interests can be examined more closely and can serve as basis for the successful continued existence of motorsport.Parallel to this, a repeated execution of the present study is recommended in order to evaluate the attractiveness after a longer existence of SimRacing and Formula $\mathrm{E}$.

From an industry point of view, the question should be addressed as to whether this sport should continue to strive to inspire the masses, or whether a focus, for example on people with an affinity for technology, would not possibly provide more success. As a consequence, motorsport could develop into a niche sport, but would remain in the attractive for defined target audience on the long run. In order to win the Generation $Z$ as future fans, motorsports will inevitable need to keep evolving.

\author{
Authors \\ Jennifer Burg, B.Sc. \\ E-Mail: jenny-burg@gmx.de \\ Prof. Dr. Patrick Planing \\ Phone: +49 (0)711.8926-2903 \\ E-Mail: patrick.planing@hft-stuttgart.de
}




\section{Literature}

Audi AG (Hrsg.). (2016, 2. Juli). Lucas di Grassi zum Motorsport der Zukunft. Abgerufen 2. April 2020, von

https://www.audi.com/de/experience-audi/audi-sport/audi-racing/formula-e/story-di-grassi-motorsport-

future.html

Jonas, K., \& Stroebe, W. (2007). Sozialpsychologie: Eine Einführung. (M. Hewstone, Hrsg., C. Lebherz \& K. Reiss, Übers.)

(5. Aufl.). Heidelberg, Deutschland: Springer Medizin Verlag.

Kuß, A. (2012). Marktforschung (4. Aufl.). Wiesbaden, Deutschland: Gabler Verlag. https://doi.org/10.1007/978-3-8349$\underline{3853-4}$

Moosbrugger, H., \& Kelava, A. (2008). Testtheorie und Fragebogenkonstruktion. Heidelberg, Deutschland: Springer Medizin Verlag.

OC\&C Strategy Consultants (Hrsg.). (2019). Eine Generation ohne Grenzen: Generation Z wird erwachsen. Abgerufen 7. März 2020, von https://www.occstrategy.com/media/1904/eine-generation-ohne-grenzen .pdf

Reuter, B. (2018). Qualifikation im Motorsport-Management. In B. Reuter (Hrsg.), Motorsport-Management: Grundlagen - Prozesse - Visionen (S. 351-369). Wiesbaden, Deutschland: Springer Gabler. https://doi.org/10.1007/978-3$\underline{662-57703-5}$

The Nielsen Company (Hrsg.). (2019). Game Changer: Rethinking Sports Experiences For Generation Z. Abgerufen von https://www.nielsen.com/eu/en/insights/report/2019/game-changer/\# 